\title{
Endothelial Nitric Oxide Synthase (eNOS) as a Therapeutic Target in Type 2 Diabetes Mellitus and Its Vascular Complications: A Narrative Review
}

\author{
Andreliano Yosua Rompis ${ }^{1}$, Adrian Wiryanata Gorintha ${ }^{1}$, Nurmi', \\ Luh Putu Ratna Sundari ${ }^{2}$
}

${ }^{1}$ Faculty of Medicine, ${ }^{2}$ Physiology Department, Udayana University, Denpasar, Bali, Indonesia

Corresponding Author: Andreliano Yosua Rompis

DOI: https://doi.org/10.52403/ijrr.20220141

\begin{abstract}
Diabetes mellitus type 2 (T2DM) has been a global health problem. Current studies have shown that the increased mortality and morbidity in T2DM are related to vascular complications. The vascular complications were caused by increased reactive oxygen species (ROS) associated with chronic hyperglycemia and insulin resistance. The increase of ROS in T2DM was influenced by the p38 MAPK pathway which is directly related to the modulation of nitric oxide (NO) produced by endothelial nitric oxide synthase (eNOS) of endothelium cells. The decrease of $\mathrm{NO}$ by eNOS also has a connection with an event known as eNOS uncoupling. The decrease of eNOS plays a role in the pathogenesis of T2DM and its vascular complications such as increased inflammatory pro-cytokine, activation of NADPH pathway, increased of AGEs, VCAM1, ICAM-1, and also the activation of protein kinase $\mathrm{c}$ and Rho-kinase pathway. Some interventions indirectly or directly have modulated NO relayed to its work targets such as oral antidiabetic drugs (metformin, sulfonylurea, and acarbose) or some polyphenol compounds such as emodin, $\alpha$-Lipoic acid, curcumin, and olive oil. Modulation of NO in these interventions can be strong evidence that NO can be a target for further therapy in the management of T2DM and its complications.
\end{abstract}

Keywords: eNOS, vascular complication, Type 2 Diabetes mellitus

\section{INTRODUCTION}

Diabetes mellitus (DM) is a metabolic disease characterized by hyperglycemia. Hyperglycemia is defined as a condition of increasing blood sugar levels exceeding the normal limit with one of the parameters, namely fasting blood sugar (GDP) levels of more than $126 \mathrm{mg} / \mathrm{dl} .{ }^{1} \mathrm{DM}$ is a health problem that is a threat worldwide. Based on data from the World Health Organization (WHO) in 2014, the number of DM sufferers worldwide is around $4.7 \%$. This figure is estimated to double to $8.5 \%$ in $2016 .^{2}$ Data from the International Diabetes Federation (IDF) in 2019 showed $9.3 \%$ of the world's population was diagnosed with DM and this figure is also estimated to increase by around $51 \%$ by $2045 .^{3}$

Diabetes mellitus consists of type 1 diabetes mellitus (T1DM) and type 2 diabetes mellitus (T2DM). T1DM is DM caused by an autoimmune reaction that attacks pancreatic beta cells so that insulin production is disrupted, while T2DM is DM which is identical to insulin resistance. Of the two types of DM, T2DM is the most common DM. ${ }^{2,4}$ As a chronic disease, T2DM can cause various complications that affect the mortality and morbidity of the sufferer. ${ }^{5}$ Complications in T2DM can be vascular complications and nonvascular complications. Nonvascular complications in T2DM include gastroparesis, infection, 
skin changes, and loss of hearing loss, while vascular complications are further subdivided into microvascular and macrovascular. ${ }^{6} \quad$ Microvascular complications include diabetic retinopathy, diabetic nephropathy, and diabetic neuropathy. Macrovascular complications of diabetes mellitus include coronary artery disease (CAD), peripheral arterial disease (PAD), and cerebrovascular disease. ${ }^{6}$ Research shows that $70 \%$ of DM deaths or mortality are related to vascular complications. $^{7}$ Data from the IDF also shows that $21 \%$ of CAD and $32 \%$ of other heart diseases are found in people with DM in countries with upper-middle income. ${ }^{3}$

The association of vascular complications in T2DM cannot be separated from the p38 mitogen-activated protein kinase (p38MAPK) pathway which triggers an increase in reactive oxygen species (ROS) levels. In addition, this pathway also increases the activity of inflammatory procytokines such as tumor necrosis alpha (TNF- $\alpha$ ), IL-1beta, and IL-6. ${ }^{8-12}$ This pathway also modulates the NADPH pathway so that oxidative stress increases. The activation of these pathways is supported by the hyperglycemia and insulin resistance that occurs in T2DM. Consequently, these conditions affect the bioavailability of NO. ${ }^{13}$ Reduced NO levels were accompanied by an increase in various molecules such as advanced glycosylated end products (AGEs), vascular adhesion molecule 1 (VCAM-1), intracellular adhesion molecule 1 (ICAM-1), cyclooxygenase-2 (COX-2), and reduced insulin sensitivity. ${ }^{14-16}$ Decreased NO levels in T2DM are also associated with a mechanism known as eNOS uncoupling. eNOS uncoupling is associated with various cardiovascular diseases in DM in general. eNOS uncoupling can increase oxidative stress by producing superoxide (SO) instead of NO production. An increase in $\mathrm{SO}$ and a decrease in NO will activate an increase in ICAM-1 and the activation of several pathways such as protein kinase $\mathrm{C}$ and Rhokinase that can induce vascular complications such as diabetic nephropathy and retinopathy. ${ }^{17}$

The relationship between eNOS in the pathogenesis of T2DM can be used as a therapeutic target in developing advanced treatments or interventions for T2DM and its vascular complications. As a therapeutic target, NO production by eNOS can be modulated by various interventions. Even some of the interventions currently used, such as oral antidiabetic drugs, including sulfonylureas, acarbose, and metformin, work by influencing NO levels in T2DM patients. In addition, various studies prove that NO has an association in the treatment of T2DM and its complications. Further understanding of $\mathrm{NO}$ as a therapeutic target could lead to a comprehensive development of the management of T2DM and its complications in the future. ${ }^{18-19}$

\section{METHOD}

The literature search was conducted from November, $22^{\text {nd }}$ to December, $15^{\text {th }}$ 2021 using two databases, namely Pubmed and Google Scholar with the keywords used were "diabetes mellitus and nitric oxide", "Diabetes mellitus and cardiovascular", and "Diabetes mellitus and cardiovascular". vascular and complications." The inclusion criteria used were all studies that discussed T2DM which is associated with eNOS and vascular complications. After that, screening was carried out so that the appropriate $\mathrm{X}$ was obtained, seven from Google Scholar and 50 from Pubmed. Furthermore, the entire literature obtained was critically examined by considering the aspects of validity, importance, and applicability. The data obtained are then synthesized systematically and logically.

\section{DISCUSSION}

\section{Diabetes mellitus and cardiovascular disease}

Diabetes mellitus (DM) is a metabolic disease characterized by hyperglycemia due to impaired insulin secretion, insulin function, or both. ${ }^{1} \mathrm{DM}$ is divided into two types, namely diabetes 
mellitus type 1 (T1DM) and diabetes mellitus type 2 (T2DM). Based on the types of DM, T2DM is the most common type of diabetes Mellitus. $^{2}$

Type 2 diabetes mellitus is a type of DM associated with insulin resistance. Insulin resistance is a condition when insulin cannot work properly, even though insulin has been secreted in normal amounts. This results in impaired glucose uptake in peripheral tissues. ${ }^{20}$ If this condition is maintained, then T2DM can have an impact on vascular and nonvascular complications. Non-vascular complications can be in the form of gastroparesis, infection, changes in the skin, and loss of hearing loss, while vascular complications are subdivided into macrovascular and microvascular.

Macrovascular complications in T2DM can be in the form of coronary heart disease, blood vessel disease in the brain and peripherals, while microvascular complications are related to diabetic retinopathy, neuropathy, myopathy, and nephropathy. ${ }^{6}$ Studies have shown that patients with T2DM have an accelerated and increased incidence of atherosclerotic vascular lesions. ${ }^{21}$ In addition, cardiovascular diseases such as myocardial infarction and stroke are two to four times higher in people with T2DM than in people with or without T2DM. ${ }^{21-22}$

\section{Epidemiology of Diabetes Mellitus}

Diabetes mellitus is one of the health problems in the world today. Data from the world health organization (WHO) shows the prevalence of DM sufferers in the world population over 18 years was $8.5 \%$ in 2014 . This data tends to increase when compared to 1980 with $4.7 \% .^{2}$ In addition to $\mathrm{WHO}$, data from the international diabetes federation (IDF) in 2019 showed as many as 463 million or $9.3 \%$ of the world's population were diagnosed with DM and it is estimated that this number will continue to increase by $51 \%$ in 2045 to 700 million sufferers. ${ }^{3}$ In terms of aging itself, it is known that DM increases as a person ages. ${ }^{3}$
This situation is supported by data that in adults aged 20 to 24 years the prevalence of DM was found to be around $1.4 \%$ while in adults aged 75-79 years the prevalence of DM was $19.9 \% .^{3}$

In addition to the high incidence, DM also affects morbidity and mortality in the world's population. Data from the IDF shows that $11.3 \%$ of deaths that occur in the world are related to DM. ${ }^{3}$ These data also show that 4.2 million adults aged 20 to 79 years are estimated to die from DM and its complications. These high numbers are associated with comorbid diseases that are often experienced by DM patients such as CAD. Research has shown that there is a $21 \%$ association between CAD and adults with DM in upper-middle-income countries. ${ }^{23}$ In addition, it was found that $32 \%$ of other cardiovascular diseases also had a similar relationship with DM sufferers in upper-middle-income countries. ${ }^{23}$ Elevated blood sugar levels or hyperglycemia has also been associated with a $15 \%$ responsibility for deaths related to cardiovascular disease and kidney disease. ${ }^{24}$ Another study also showed that $32.2 \%$ of patients with cardiovascular disease, $29.1 \%$ of people with atherosclerosis, $21.2 \%$ of coronary heart disease, $14.9 \%$ of heart failure, $14.6 \%$ of angina, $10 \%$ of myocardial infarction, and $7,6 \%$ of strokes in a cross-sectional study of 57 research articles were associated with T2DM. The total number of samples in this cross-sectional study was 4,548,481 T2DM patients. ${ }^{25}$

\section{Nitric oxide synthase (NOS)}

Nitric oxide (NO) is an endothelialderived relaxing factor (EDRF) compound produced by endothelial cells. NO is a potent vasodilator synthesized due to the stimulation of bradykinin. NO has various roles with different molecular targets. NO can act as a regulator of neurotransmission, vascular tone, regulate gene transcription and mRNA translation, and posttranslational protein production. ${ }^{26}$ Nitric oxide synthase consists of three types of 
isoenzymes, namely endothelial nitric oxide synthase (eNOS), inducible nitric oxide synthase (iNOS), and neuronal nitric oxide synthase (nNOS). eNOS enzyme is a type of enzyme that acts as a producer of most of the NO in normal vessels by endothelial cells of arteries, veins, and also platelets that are dependent on calcium $(\mathrm{Ca})$. nNOS is a special form of eNOS that plays a role in the nervous system while iNOS is a type of enzyme that is present and induced by macrophage cells, myocytes, and small blood vessel cells which are regulated by pro-cytokines and endotoxins. NO itself is synthesized by endothelial cells from Larginine and molecular oxygen with the help of cofactors bihydrobiopterin (BH4) and flavin adenine dinucleotide (FAD).

All NOS isoenzymes use L-arginine as a substrate and molecular oxygen and reduce NADPH as a co-substrate. In addition, the NOS synthesis process requires various cofactors such as flavin adenine dinucleotide (FAD), flavin mononucleotide $(\mathrm{FMN})$, and tetrahydro-L-biopterin (BH4). In the process, NOS will transfer electrons from the co-substrate NADPH via FAD and FMN in the carboxy-terminal reductase domain to haem in the oxygenase domain. The oxygenase domain then binds to the essential cofactor $\mathrm{BH} 4$, molecular oxygen, and the substrate L-arginine. ${ }^{26-27}$ In the oxygenase domain, electrons are used to activate molecular oxygen and oxidize Larginine to L-citrulline and NO. The decrease in the amount of $\mathrm{NO}$ or the inactivation of $\mathrm{NO}$ will form a superoxide anion (O2-) which causes oxidative damage. ${ }^{26}$

\section{Endothelial nitric oxide (eNOS) in type 2 diabetes mellitus and its association with vascular complications}

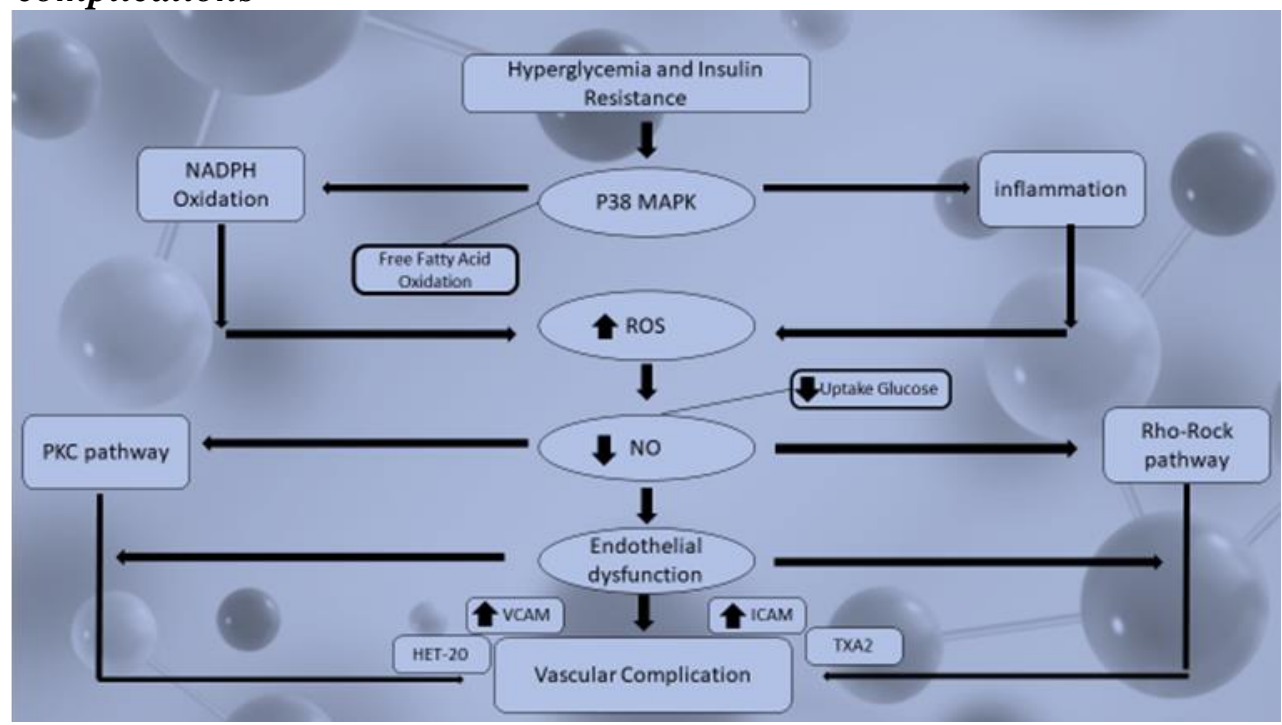

Figure 1: eNOS and its association with DMT2 Pathogenesis ${ }^{9-12,14-15}$

The association between T2DM and vascular complications cannot be separated from an initial condition known as endothelium dysfunction. Normally, each cell has been designed in such a way to be able to withstand any changes that occur. However, when the adaptive capacity of a cell reaches its limit, homeostasis in the body can be disturbed causing morphological changes in the cell itself. The endothelium is a layer that lines the inner walls of blood vessels and plays a role in vascular homeostasis including vascular integrity, blood flow, cell adhesion, angiogenesis, vascular permeability, immune response, and metabolism. ${ }^{28}$ In maintaining vascular homeostasis, the endothelium also releases several vasoactive mediators. The main mediator that plays an important role in $\mathrm{NO}$ or eNOS. Under physiological conditions, increased blood glucose will trigger the release of insulin by 
pancreatic beta cells. The release of insulin will activate eNOS so that NO production will increase. Increased production of eNOS will cause blood vessels to dilate thereby helping glucose uptake by peripheral tissues. ${ }^{29}$ T2DM, which is characterized by insulin resistance and hyperglycemia, affects NO production by the endothelium. ${ }^{30}$ This state activates a pathway known as P38MAPK. The activation of this pathway has an impact on the state of hyperinsulinemia and atherogenesis. ${ }^{28,31}$ This situation will trigger an increase in free fatty acids and pro-inflammatory cytokines that trigger an increase in reactive oxygen species (ROS). ${ }^{32}$ The inflammatory procytokines involved consist of IL-1beta and IL-6. A case-control study conducted by European Prospective Investigation showed that there was an increase in the levels of IL-1beta and IL-6 in patients with T2DM. ${ }^{8}$ The increase of these two inflammatory procytokines is associated with inflammation in the pathogenesis of T2DM. In addition to IL-1beta and IL-6, tumor necrosis factor- $\alpha$ $(\mathrm{TNF}-\alpha)$ also plays a role in regulating immune cells and inflammatory procytokines. An increase in TNF- was found in hyperglycemic states followed by an increase in IL-6. ${ }^{11}$ Research has shown that increased ROS in DM is associated with activation of the NADPH-dependent pathway that increases the amount of oxidative stress in the body. ${ }^{33}$ The reduction in NO also induces the activity of endothelium-derived hyperpolarizing factors such as cyclooxygenase (COX-2). In addition, this state also activates TXA2 and an increase in 20-HETE levels. ${ }^{14-15}$ An increase in 20-HETE will inhibit the PIK/Akt pathway, including binding between insulin and insulin receptor substrate 1 (IRS-1). The reduced NO production by eNOS also increases advanced glycation end-products (AGEs) and NFkB and other adhesion molecules such as VCAM-1 AND ICAM-1. ${ }^{34}$ This increase in adhesion molecules affects the adhesion of leukocytes to the endothelium surface which will have an impact on vascular complications. Activation of the p38 MAPK pathway will also activate other pathways such as the protein kinase $\mathrm{C}$ pathway and the Rho-associated protein kinase (ROCK) pathway. ${ }^{35-36}$ The mechanism or description of the p38 MAPK pathway can be seen in Figure 1.

\section{eNOS Uncoupling in Diabetes mellitus}

The association of vascular complications in DM is also associated with a mechanism known as eNOS uncoupling. This event is associated with a decrease in eNOS in both T1DM and T2DM DM. Normally; eNOS is activated together with several cofactors and substrates such as tetrahydrobiopterin (BH4), L-arginine, and eNOS S-glutathionylation as well as molecular oxygen. These cofactors and substrates play an important role in producing NO. Disruption of these molecules will cause eNOS uncoupling which effects on increases ROS and endothelium dysfunction. ${ }^{26,37-38}$ Uncoupling of eNOS has been found in various DM research models. It is associated with deficiencies of eNOS cofactors such as BH4 deficiency, L-arginine deficiency, and eNOS S-glutathionylation deficiency. ${ }^{39-40}$

BH4 deficiency in T2DM occurs due to two mechanisms. First, BH4 deficiency occurs due to increased blood sugar so that the MAPK or p38 MAPK pathway is activated which results in the activation of protein kinase $\mathrm{C}$ (PKC). In addition, this mechanism is accompanied by an increase in ROS due to the high activation of NADPH oxidase. ${ }^{40-41}$ Second, this situation is related to the reduced biosynthesis of BH4. Research shows that the increased production of ROS in DM causes the activation of prosthetic degradation of the GCH1 enzyme. This enzyme plays a role in the synthesis of BH4. ${ }^{42}$ The increase in ROS was followed by an increase in several compounds that inhibit the eNOS cofactor in producing $\mathrm{NO}$ such as superoxide (SO) and peroxynitrite which can oxidize $\mathrm{BH} 4$ to $\mathrm{BH} 2 .{ }^{43}$ The oxidation of $\mathrm{BH} 4$ to $\mathrm{BH} 2$ causes $\mathrm{BH} 2$ to bind to eNOS so that $\mathrm{NO}$ production 
is disrupted. Nitric oxide (NO) could not be produced but $\mathrm{NO}$ would be replaced by $\mathrm{SO}$ production which has an impact on increasing oxidative stress. Research on fructose-induced DM rats showed that $\mathrm{BH} 4$ levels in the rat aorta decreased. On the other hand, there was an increase in $\mathrm{BH} 2$ levels in these mice. ${ }^{44}$ The relationship between $\mathrm{BH} 4$ and $\mathrm{NO}$ was further strengthened by studies showing that endothelial dysfunction in DM can be reduced by ex vivo incubation of $\mathrm{BH} 4 .{ }^{45}$ Apart from BH4 deficiency, reduced NO production may also be due to L-arginine substrate deficiency associated with arginase induction. Arginase induction in DM occurs due to hyperglycemia, which then activates arginase I through the activation of the RhoA-Rock pathway, which affects leukocyte adhesion through activation of the ICAM-1 molecule, increased endothelial permeability, and inactivation of eNOS which causes microvascular damage so that diabetic retinopathy can end. ${ }^{46}$ This situation is supported by studies in streptozotocininduced mice which showed that there was excessive activation of arginase $\mathrm{I}$ in the coronary arteries and activation of arginine II in the mesenteric arteries. The presence of arginase activation in T1DM and T2DM suggests that reduced NO production reduces vascular vasodilation and contributes to endothelium dysfunction. ${ }^{47}$

\section{eNOS as a therapeutic target in diabetes mellitus}

eNOS can be used as glycemic control in patients with T2DM. Glycemic control in T2DM is important as therapy for the underlying disease and its complications, eNOS can be modulated by oral antidiabetic drugs such as sulfonylurea and acarbose. Aydin et al study showed that NO levels in T2DM patients, when given oral antidiabetic drugs such as sulfonylurea, were significantly higher than the control group. This shows that NO modulation also has a certain level of contention which is still a matter of controversy. ${ }^{18}$ Other studies with metformin have shown that metformin modulates or affects $\mathrm{NO}$ production in T2DM patients. Metformin can increase endothelial precursor cells (EPCs) which is correlated with an increase in $\mathrm{NO}$ and a decrease in superoxide (SO). An in vivo study in DM rats by Han et al who was given metformin showed that there was an increase in intracellular NO levels in the bone marrow EPCs of T2DM rats compared to the control group, namely non-diabetic rats $(\mathrm{P}<0.001)$. In addition, this study also showed that the metformin group significantly $\quad(\mathrm{P}<0.05) \quad$ decreased intracellular superoxide levels in bone marrow EPCs of T2DM mice. ${ }^{19}$ Olive oil intervention also affected modulating NO in eNOS. Giving olive oil to ECV304 cells that have been modified into endothelial cells with low blood sugar and intracellular NO levels showed an increase in NO levels after being given olive oil polyphenol extract. The increase in NO level in this intervention was associated with an increase in calcium ions induced by acetylcholine. The increase in eNOS is thought to be related to the activation of the PI3/Akt pathway as a substitute for MAPK. The activation of this pathway is associated with a decrease in the levels of ROS present followed by glucose uptake in peripheral tissues. ${ }^{49}$

\section{eNOS Targets on Macrovascular Complications of Diabetes Mellitus}

Coronary artery disease (CAD) is one of the macrovascular complications of diabetes mellitus. Coronary artery disease itself is one of the most common causes of death in the world that can arise due to a combination of genetic and environmental factors. Most patients with CAD themselves experience endothelial dysfunction at an early stage where the main feature of endothelial dysfunction is an impaired amount of nitric oxide (NO). Nitric oxide acts as a vasodilator of blood vessels, the availability of $\mathrm{NO}$ itself is influenced by the presence of endothelial nitric oxide (eNOS). In a case-control study in a population in Tunisia, it was found that the $894 \mathrm{G}>\mathrm{T}$ 
mutation was associated as a risk factor for CAD. ${ }^{50}$ On the other hand. Other studies have shown that there is an association between CAD and eNOS 4b/a polymorphism in African populations. ${ }^{51}$ Other studies have also shown that the presence of $-786 \mathrm{~T}>\mathrm{C}$ polymorphism in the promoter region of eNOS increases the risk of developing CAD. ${ }^{52}$

In the South Korean population, eNOS gene polymorphisms, especially type $-786 \mathrm{~T}>\mathrm{C}, 4 \mathrm{~b}$ and $894 \mathrm{G}>\mathrm{T}$, are known to be risk factors for the incidence of ischemic stroke in patients with type 2 diabetes mellitus in South Korea. ${ }^{53}$ Studies in diabetic rats have shown that there is a decrease in the amount of phosphorylation of eNOS which is also associated with impaired vascular reactions, hypertension, and greater stroke size in Middle Cerebral Artery occlusion. ${ }^{54}$ Further studies have shown that the eNOS $894 \mathrm{G}>\mathrm{T}$ mutation plays a role in increasing the risk of ischemic stroke. ${ }^{55}$

Peripheral arterial disease (PAD) is a manifestation of the presence of systemic atherosclerosis that occurs at a different location from coronary arterial disease (CAD). PAD is associated with an increased risk of cardiovascular and cerebrovascular disorders. Studies show that in smokers the eNOS-786T $>$ C mutation increases, thereby increasing the incidence of PAD ${ }^{56}$ Followup studies also showed that the rs 1799983 polymorphism in the eNOS gene was significantly associated with the presence of PAD. ${ }^{57}$

\section{eNOS Targets on Microvascular Complications of Diabetes Mellitus}

Diabetic nephropathy (DN) is a major cause of End-Stage Renal Disease (ESRD) and is also one of the main complaints of patients with type 2 diabetes mellitus. in the eNOS gene. ${ }^{58} \mathrm{~A}$ similar study was also conducted in the Czech Republic where the results obtained are consistent with the results obtained by previous studies. ${ }^{59}$ A study in a population in Tunisia showed that patients with diabetic retinopathy (DR) had polymorphism $4 \mathrm{~b} / 4 \mathrm{a}$ and $-786 \mathrm{~T} / \mathrm{C}$ significantly. ${ }^{60}$ Other studies have shown that polymorphisms in eNOS G894T increase the likelihood of DR by increasing the pressure on the retina. ${ }^{61}$ Decreased AMPK-eNOS bioavailability triggers the development of diabetic peripheral neuropathy (DPN) by increasing the rate of apoptosis and decreasing the rate of autophagy due to oxidative stress. ${ }^{62}$ In addition, in another study, patients with the genotype 'aa' in eNOS type 27VNTR (a/b) had a high risk of developing DPN. ${ }^{63}$

\section{CONCLUSION}

Seeing the vital role of eNOS in the process of vascular endothelial dysfunction, eNOS is a promising potential as a therapeutic target in the treatment of vascular complications of diabetes mellitus. Several studies have shown that increased eNOS can affect oxidative stress, glycemic control, and vascular complications.

\section{Acknowledgement: None}

\section{Conflict of Interest: None}

\section{Source of Funding: None}

\section{REFERENCES}

1. PerkumpulanEndokrinologi Indonesia. Konsesuspengelolaan dan pencegahaan diabetes melitus tipe 2 di Indonesia tahun 2015. Jakarta: PB. Perkeni;2015.

2. World Health Organization. Diabetes [internet]. Geneva: world health organization; 2018 [disitasi 15 desember 2019]. Tersedia di: https://www.who.int/news-room/factsheets/detail/diabetes

3. International diabetes federation. IDF diabetes atlas. 9th edition. IDF;2019.

4. Departemen Kesehatan Republik Indonesia. Hasil Riskesdas 2018. Jakarta: Depkes RI;2018.

5. Orasanu G, dan Plutzky J. The pathologic continuum of diabetic vascular disease. Journal of the American College of Cardiology. 2009;53(5):35-42. 
6. Kasper D, Fauci A, Hauser S, Longo D, Jameson J, Loscalzo J. Harrison's principles of internal medicine, $19 \mathrm{e}$.

7. Kibel A, Selthofer-Relatic K, Drenjancevic I, Bacun T, Bosnjak I, Kibel D, Gros M. Coronary microvascular dysfunction in diabetes mellitus. Journal of International Medical Research. 2017 Dec;45(6):1901-29.

8. Spranger J, Kroke A, Mohlig M, Hoffman $\mathrm{K}$, Bergmann MM, Ristow M, Boeing $\mathrm{H}$, dan Pfeiffer. Inflammatory cytokines and the risk to develop type 2 diabetes. 2003;52(3):812-817.

9. Geisler T, Mueller K, Aichele S, Bigalke B, Stellos K, Htun P, Ninci E, Susanne Fateh M, May AE, dan Gawaz M. Impact of inflammatory state and metabolic control on responsiveness to dual antiplatelet therapy in type 2 diabetics after PCI: prognostic relevance of residual platelet aggregability in diabetics undergoing coronary interventions. 2010;99(11):743-752.

10. Pecoits-Filho R, Barany P, Lindholm B, Heimbürger $O$, dan Stenvinkel, $P$. Interleukin- 6 is an independent predictor of mortality in patients starting dialysis treatment. Nephrology Dialysis Transplantation. 2002;17(9):1684-1688.

11. Wasmuth HE, Kunz D, Graf J, Stanzel S, Purucker EA, Koch A, Gartung C, Heintz B, Gressner A, Matern S, dan Lamert F. 2004;32(5):1109-1114.

12. Nyström T, Nygren A, dan Sjöholm $\AA$. Increased levels of tumour necrosis factor- $\alpha$ (TNF- $\alpha$ ) in patients with Type II diabetes mellitus after myocardial infarction are related to endothelial dysfunction. Clinical science. 2006;110(6):673-681.

13. Tousoulis D, Tsarpalis K, Cokkinos D, Stefanadis C. Effects of insulin resistance on endothelial function: possible mechanisms and clinical implications. Diabetes, Obesity and Metabolism. 2008 Oct;10(10):834-42.

14. Bagi, Z., Erdei, N., Papp, Z., Édes, I., \& Koller, A. (2006). Up-regulation of vascular cyclooxygenase-2 in diabetes mellitus. Pharmacological Reports, 58, 52.

15. Davel AP, Wenceslau CF, Akamine EH, et al. Endothelial dysfunction in cardiovascular and endocrine-metabolic diseases: an update. Braz J Med Biol Res 2011; 44: 920-932.

16. Li X, Zhao G, Ma B, Li R, Hong J, Liu S, Wang DW. 20-Hydroxyeicosatetraenoic acid impairs endothelial insulin signaling by inducing phosphorylation of the insulin receptor substrate-1 at Ser616. PloS one. 2014 Apr 24;9(4):e95841.

17. Halasz E dan Townes-Anderson E. Inhibitors in ocular disease. 2016;4(4):280301.

18. Aydın A, Orhan H, Sayal A, Özata M, Şahin $\mathrm{G}$, Işımer A. Oxidative stress and nitric oxide related parameters in type II diabetes mellitus: effects of glycemic control. Clinical biochemistry. 2001 Feb 1;34(1):6570.

19. Han X, Tao Y, Deng Y, Yu J, Sun Y, Jiang G. Metformin accelerates wound healing in type 2 diabetic $\mathrm{db} / \mathrm{db}$ mice. Molecular medicine reports. 2017 Dec 1;16(6):8691-8.

20. Toursolis D, Papageorgiou N, AndrolaukisE,Siasos G, Latsios G, Tentolouris K, dan Stefanadis. Diabetes melitus-associated vascular impairment. 2013;62(8):667-76.

21. Haffner SJ and Cassells H. Hyperglycemia as a cardiovascular risk factor. Am J Med 2003; 115(Suppl 8A): 6S-11S.

22. Haffner SM, Lehto S, Ro“ nnemaa T, et al. Mortality from coronary heart disease in subjects with type 2 diabetes and in nondiabetic subjects with and without prior myocardial infarction. N Engl J Med 1998; 339: 229-234

23. Ramachandran A, Snehalatha C. Diabetes prevention programs. Med Clin North Am. 2011 Mar;95(2):353-72, viii;

24. Buchanan TA, Xiang AH, Peters RK, Kjos SL, Marroquin A, Goico J, Ochoa C, Tan S, Berkowitz K, Hodis HN, Azen SP. Preservation of pancreatic $\beta$-cell function and prevention of type 2 diabetes by pharmacological treatment of insulin resistance in high-risk Hispanic women. Diabetes. 2002 Sep 1;51(9):2796-803.

25. Einarson TR, Annabel A, dan Ludwig C. Prevalence of cardiovascular disease in type 2 diabetes: a systematic literature review of scientific evidence from across the world in 2007-2017. Cardiovascular diabetology. 2018;17(1):83.

26. Forstermann U dan Sessa WC. Nitric oxide synthases: regulation and function. European heart journal. 2012;33(7):829837.

27. Alderton WK, Cooper CE, Knowles RG. Nitric oxide synthases: structure, function 
and inhibition. Biochem J. 2001;357:593615.

28. Sena CM, Pereira AM, Seiça R. Endothelial dysfunction- a major mediator of diabetic vascular disease. Biochimica et Biophysica Acta (BBA)-Molecular Basis of Disease. 2013 Dec 1;1832(12):2216-31.

29. Kibel A, Selthofer-Relatic K, Drenjancevic I, Bacun T, Bosnjak I, Kibel D, Gros M. Coronary microvascular dysfunction in diabetes mellitus. Journal of International Medical Research. 2017 Dec;45(6):1901-29.

30. Okon EB, Chung AW, Rauniyar P, Padilla E, Tejerina T, McManus, Honglin L, dan Breeman CV. Compromised arterial function in human

31. type 2 diabetic patients. Diabetes 2005; 54 : 2415-2423.

32. Roberts AC and Porter KE. Cellular and molecular mechanisms of endothelial dysfunction in diabetes. Diab Vasc Dis Res 2013; 10: 472-482.

33. Shanik MH, Xu Y, Škrha J, Dankner R, Zick Y, Roth J. Insulin resistance and hyperinsulinemia: is hyperinsulinemia the cart or the horse?. Diabetes care. 2008 Feb 1;31(Supplement 2):S262-8.

34. Eid S, Abou-Kheir W, Sabra R, Daoud G, Jaffa A, Ziyadeh FN, Roman L, Eid AA. Involvement of renal cytochromes $\mathrm{P} 450$ and arachidonic acid metabolites in diabetic nephropathy. Journal of biological regulators and homeostatic agents. $2013 \mathrm{Jul}$ 1;27(3):693-703.

35. Meigs JB, Larson MG, Fox CS, Keaney JF, Vasan RS, dan Benjamin, EJ. Association of oxidative stress, insulin resistance, and diabetes risk phenotypes: the Framingham Offspring Study. DNoh, H., \& King, G. L. (2007). The role of protein kinase C activation in diabetic nephropathy. Kidney International, 72, S49-S53. iabetes care. 2007;30(10):2529-2535.

36. Noh H,dan King GL. The role of protein kinase $\mathrm{C}$ activation in diabetic nephropathy. Kidney International. 2007;72:49-53.

37. Zhou H dan Li YJ. Rho kinase inhibitors: potential treatments for diabetes and diabetic complications. Current pharmaceutical design. 2012;18(20):29642973.

38. $\mathrm{Li} \mathrm{H}$, Forstermann U. Prevention of atherosclerosis by interference with the vascular nitric oxide system. Curr Pharm Des 2009;15(27):3133-45.
39. Zweier JL, Chen CA, Druhan LJ. Sglutathionylation reshapes our understanding of endothelial nitric oxide synthase uncoupling and nitric oxide/reactive oxygen species-mediated signaling. Antioxid Redox Signal 2011; 14(10):1769-75.

40. Schuhmacher S, Oelze M, Bollmann F, Kleinert H, Otto C, Heeren T, Steven S, Hausding M, Knorr M, Pautz A, Reifenberg $\mathrm{K}$. Vascular dysfunction in experimental diabetes is improved by pentaerithrityl tetranitrate but not isosorbide-5-mononitrate therapy. Diabetes. 2011 Oct 1;60(10):260816.

41. Alp NJ, Mussa S, Khoo J, Cai S, Guzik T, Jefferson A, Goh N, Rockett KA, Channon KM. Tetrahydrobiopterin-dependent preservation of nitric oxide-mediated endothelial function in diabetes by targeted transgenic GTP-cyclohydrolase I overexpression. The Journal of clinical investigation. 2003 Sep 1;112(5):725-35.

42. Hink U, Tsilimingas N, Wendt M, Münzel T. Mechanisms underlying endothelial dysfunction in diabetes mellitus. Treatments in endocrinology. 2003 Oct;2(5):293-304. Mechanisms underlying endothelial dysfunction in diabetes mellitus. Circ Res 2001;88(2):E14-22 (5):725-35.

43. Xu J, Wu Y, Song P, Zhang M, Wang S, Zou MH. Proteasome-dependent degradation of guanosine 5'-triphosphate cyclohydrolase I causes tetrahydrobiopterin deficiency in diabetes mellitus. Circulation 2007;116(8):944-53.

44. Laursen JB, Somers M, Kurz S, McCann L, Warnholtz A, Freeman BA, Tarpey M, Fukai T, Harrison DG. Endothelial regulation of vasomotion in apoE-deficient mice: implications for interactions between peroxynitrite and tetrahydrobiopterin. Circulation. 2001 Mar 6;103(9):1282-8.

45. Shinozaki K, Kashiwagi A, Nishio Y, Okamura T, Yoshida Y, Masada M, Toda $\mathrm{N}$, Kikkawa R. Abnormal biopterin metabolism is a major cause of impaired endothelium-dependent relaxation through nitric oxide/O2-imbalance in insulinresistant rat aorta. Diabetes. 1999 Dec 1;48(12):2437-45.

46. Pannirselvam M, Verma S, Anderson TJ, Triggle CR. Cellular basis of endothelial dysfunction in small mesenteric arteries from spontaneously diabetic $(\mathrm{db} / \mathrm{db}-/-)$ 
mice: role of decreased tetrahydrobiopterin bioavailability. $\mathrm{Br}$ J Pharmacol 2002; 136(2):255-63.

47. Pernow J, Kiss A, Tratsiakovich Y, Climent B. Tissue-specific upregulation of arginase I and II induced by p38 MAPK mediates endothelial dysfunction in type 1 diabetes mellitus. Br J Pharmacol 2015;172(19): 4684-98.

48. Beleznai T, Feher A, Spielvogel D, Lansman SL, Bagi Z. Arginase 1 contributes to diminished coronary arteriolar dilation in patients with diabetes. Am J Physiol Heart Circ Physiol 2011;300(3):H777-83.

49. Shemyakin A, Kövamees O, Rafnsson A, Böhm F, Svenarud P, Settergren M, Jung C, Pernow J. Arginase inhibition improves endothelial function in patients with coronary artery disease and type 2 diabetes mellitus. Circulation. 2012 Dec 18;126(25):2943-50.

50. Storniolo CE, Roselló-Catafau J, Pintó X, Mitjavila MT, Moreno JJ. Polyphenol fraction of extra virgin olive oil protects against endothelial dysfunction induced by high glucose and free fatty acids through modulation of nitric oxide and endothelin-1. Redox Biology. 2014 Jan 1;2:971-7.

51. Ben Ali M, Messaoudi S, Ezzine $\mathrm{H}$, Mahjoub T. Contribution of eNOS variants to the genetic susceptibility of coronary artery disease in a Tunisian population. Genetic testing and molecular biomarkers. 2015 Apr 1;19(4):203-8.

52. Yang Y, Du K, Liu Z, Lu X. Endothelial nitric oxide synthase (eNOS) 4b/a gene polymorphisms and coronary artery disease: evidence from a meta-analysis. Int $\mathrm{J}$ Mol Sci. 2014;15(5):7987-8003.

53. Liu, D. Association between the -786T $>\mathrm{C}$ 1polymorphism in the promoter region of endothelial nitric oxide synthase (eNOS) and risk of coronary artery disease: A systematic review and meta-analysis. Gene. 2014; 545;175-183.

54. Kim OJ, Kim UK, Oh SH, Cho YW, Oh KI, Oh D, Park YS, Kim NK. Association of endothelial nitric oxide synthase polymorphisms and haplotypes with ischemic stroke in Korean individuals with or without diabetes mellitus. Molecular medicine reports. 2010 May 1;3(3):509-13.

55. Li Q, Atochin D, Kashiwagi S, Earle J, Wang A, Mandeville E, Hayakawa K, d'Uscio LV, Lo EH, Katusic Z, Sessa W.
Deficient eNOS phosphorylation is a mechanism for diabetic vascular dysfunction contributing to increased stroke size. Stroke. 2013 Nov;44(11):3183-8.

56. Wei LK, Au A, Menon S, Griffiths LR, Kooi CW, Irene L, Zhao J, Lee $\mathrm{C}$, Alekseevna AM, Hassan MR, Aziz ZA. Polymorphisms of MTHFR, eNOS, ACE, AGT, ApoE, PON1, PDE4D, and ischemic stroke: meta-analysis. Journal of Stroke and Cerebrovascular Diseases. 2017 Nov 1;26(11):2482-93.

57. Sticchi E, Sofi F, Romagnuolo I, Pratesi G, Pulli R, Pratesi C, Abbate R, Fatini C. eNOS and ACE genes influence peripheral arterial disease predisposition in smokers. Journal of vascular surgery. 2010 Jul 1;52(1):97-102.

58. Dong J, Ping Y, Wang Y, Zhang Y. The roles of endothelial nitric oxide synthase gene polymorphisms in diabetes mellitus and its associated vascular complications: a systematic review and meta-analysis. Endocrine. 2018 Nov;62(2):412-22.

59. Huo P, Zhang D, Guan X, Mei Y, Zheng H, Feng $X$. Association between genetic polymorphisms of ACE \& eNOS and diabetic nephropathy. Molecular biology reports. 2015 Jan 1;42(1):27-33.

60. Kuricová K, Tanhäuserová V, Pácal L, Bartáková V, Brožová L, Jarkovský J, Kaňková K. NOS3 894G> T polymorphism is associated with progression of kidney disease and cardiovascular morbidity in type 2 diabetic patients: NOS3 as a modifier gene for diabetic nephropathy? Kidney and Blood Pressure Research. 2013;38(1):92-8.

61. Midani F, Ben Amor Z, El Afrit MA, Kallel A, Feki M, Soualmia H. The Role of Genetic Variants (rs869109213 and rs2070744) Of the eNOS Gene and Bgl II in the $\alpha 2$ Subunit of the $\alpha 2 \beta 1$ Integrin Gene in Diabetic Retinopathy in a Tunisian Population. InSeminars in ophthalmology 2019 Jul 4 (Vol. 34, No. 5, pp. 365-374). Taylor \& Francis.

62. Hermans MP, Ahn SA, Rousseau MF. eNOS [Glu298Asp] polymorphism, erectile function and ocular pressure in type 2 diabetes. European journal of clinical investigation. $2012 \mathrm{Jul} ; 42(7): 729-37$.

63. Chung YC, Lim JH, Oh HM, Kim HW, Kim MY, Kim EN, Kim Y, Chang YS, Kim HW, Park CW. Calcimimetic restores diabetic peripheral neuropathy by ameliorating 
Andreliano Yosua Rompis et.al. Endothelial nitric oxide synthase (eNOS) as a therapeutic target in type 2 diabetes mellitus and its vascular complications: a narrative review

apoptosis and improving autophagy. Cell death \& disease. 2018 Nov 26;9(12):1-8.

64. Politi C, Ciccacci C, D’Amato C, Novelli G, Borgiani P, Spallone V. Recent advances in exploring the genetic susceptibility to diabetic neuropathy. diabetes research and clinical practice. 2016 Oct 1;120:198-208.
How to cite this article: Andreliano Yosua Rompis, Adrian Wiryanata Gorintha, Nurmi et.al. Endothelial nitric oxide synthase (eNOS) as a therapeutic target in type 2 diabetes mellitus and its vascular complications: a narrative review. International Journal of Research and Review. 2022; 9(1): 340-350. DOI: https:// doi.org/10.52403/ijrr.20220141 